\section{CORRECTION}

View Article Online

View Journal I View Issue

\title{
Correction: Continuous reactor for renewable methanol
}

Cite this: Green Chem., 2022, 24, 2249

DOI: $10.1039 / \mathrm{d} 2 \mathrm{gc} 90012 \mathrm{~b}$

rsc.li/greenchem

\author{
Athanasios A. Tountas, ${ }^{a}$ Geoffrey A. Ozin*b and Mohini M. Sain ${ }^{a, c}$ \\ Correction for 'Continuous reactor for renewable methanol' by Athanasios A. Tountas et al., Green \\ Chem., 2021, 23, 340-353, DOI: 10.1039/D0GC03115A.
}

The definition of 'yield of product C' or 'per-pass yield of product C' used in this article refers to the 'molar flow of product C $\left(F_{\mathrm{C}}\right.$ for example of product $\mathrm{MeOH}$ ) divided by the total outlet product stream $\left(F_{\mathrm{T}, \text { outlet }}\right.$ )', or $F_{\mathrm{C}} / F_{\mathrm{T} \text {,outlet }} \times 100$ (in mol\%). It can otherwise be called the 'product stream concentration'.

The above is not a precise definition of 'yield of product C' or $Y_{\mathrm{C} / \mathrm{A}}$, for which a precise definition is the molar flow of product $\mathrm{C}\left(F_{\mathrm{C}}\right)$ divided by the initial molar flow of reactant $\mathrm{A}\left(F_{\mathrm{A} 0}\right)$ or $F_{\mathrm{C}} / F_{\mathrm{A} 0} \times 100($ in $\%)$.

The authors regret using the former imprecise definition, which has been used consistently throughout the article and the ESI.

The following sentences should also be changed as follows:

On page 346, right column, third paragraph, "However, this SV represents a 95\% reduction in throughput compared to the best (CO-rich feed) case, with 70\% reduction in $\mathrm{MeOH}$ yield". should be changed to:

"However, this SV represents a 95\% reduction in throughput compared to the best (CO-rich feed) case, with 70\% reduction in $\mathrm{CO}_{X}$ conversion to $\mathrm{MeOH}$ ".

In the same paragraph, "The overall disadvantage of the $\mathrm{CO}_{2}$-rich pathway by taking the throughput and yield into account is 98.5\% less productive compared to the best CO-rich case". Should be changed to: "The overall disadvantage of the $\mathrm{CO}_{2}$-rich pathway by taking the throughput and $\mathrm{CO}_{X}$ conversion into account is $98.5 \%$ less productive compared to the best CO-rich case".

On page 347 , left column, first paragraph, "The intermediate-CO feed has 35\% less yield and 50\% less throughput for an overall disadvantage of $68 \%$ ". Should be changed to "The intermediate-CO feed has $35 \%$ less $\mathrm{CO}_{X}$ conversion and $50 \%$ less throughput for an overall disadvantage of $68 \% "$.

The Royal Society of Chemistry apologises for these errors and any consequent inconvenience to authors and readers.

\footnotetext{
${ }^{a}$ Department of Chemical Engineering and Applied Chemistry, University of Toronto, 200 College St., Toronto, ON, M5S 3E5, Canada

${ }^{b}$ Department of Chemistry, University of Toronto, 80 St George St., Toronto, ON, M5S 3H6, Canada. E-mail: g.ozin@utoronto.ca

${ }^{c}$ Department of Mechanical and Industrial Engineering, University of Toronto, 5 King's College Rd., Toronto, ON, M5S 3G8, Canada
} 